\title{
Synergistic toughening and compatibilisation effect of Poly(butylene succinate) in PLA/poly-caprolactone blends
}

\author{
Nikolaos Kassos ${ }^{1}$, Adrian L.Kelly ${ }^{1}$, Timothy Gough ${ }^{1}$ and Andrew A. Gill ${ }^{2}$ \\ ${ }^{1}$ Polymer IRC, School of Engineering, University of Bradford, BD7 1DP, UK \\ ${ }^{2}$ Floreon- Transforming Packaging Ltd, Kroto Innovation Centre, University of Sheffield, 318 Broad Lane, S3 \\ 7HQ, UK \\ E-mail: nkassos@student.bradford.ac.uk
}

\begin{abstract}
Binary and ternary blends of a polylactic acid matrix with polycaprolactone $(\mathrm{PCL})$ and polybutylene succinate (PBS) were produced by twin screw extrusion, containing up to $30 \mathrm{wt} \%$ loading. Mechanical, thermal and rheological characterisation techniques were used to quantify properties of the different blend formulations and miscibility was investigated using scanning electron microscopy. PCL is known to act as an impact modifier in PLA but to cause a corresponding reduction in strength. Results showed that addition of both PBS and PCL separately caused a reduction in melt viscosity, elastic modulus and tensile strength, but an increase in impact strength and strain at break. Analysis of morphology suggested that immiscibility was evident, particularly at higher PCL and PBS loadings. Results indicated that incorporation of a small loading of PBS had a synergistic effect on the PLA-PCL blend properties. Miscibility was improved and enhanced mechanical properties were observed for a ternary blend containing $5 \mathrm{wt} \%$ of both PBS and PCL compared to blends containing $10 \%$ of each polymer alone.
\end{abstract}

Keywords: polylactic acid, toughness, blends, bioplastics, biodegradable, mechanical properties, rheology, phase separation 


\section{Introduction}

Many bioplastics are considered to be biodegradable, meaning they can be degraded by microbes under suitable conditions [1], although technically all plastics are biodegradable to some extent. Although many production routes exist, lactic acid is most commonly produced by the fermentation of glucose at $40-45{ }^{\circ} \mathrm{C}$ in the presence of microorganisms, using water as a solvent $[2,3]$. There are two ways of synthesizing PLA, by direct polycondensation of lactic acid in the presence of catalyst at low pressure or by ring opening polymerisation [4]. PLA can range from completely amorphous to highly crystalline, and because of its clarity and glossy surface is developing as an effective material for numerous applications such as packaging, fabrics and tableware. PLA has a glass transition temperature $(\mathrm{Tg})$ around $50-60{ }^{\circ} \mathrm{C}$, while the melting temperature $(\mathrm{Tm})$ is relatively low $\left(130-175{ }^{\circ} \mathrm{C}\right)$. Elastic modulus of PLA ranges between 2 and $3 \mathrm{GPa}$ with a yield point at 53-70 MPa and tensile strength of 44-66 MPa [5]. There are many ways of modifying the properties of PLA, both during processing (conditions, orientation) and post-processing (annealing). Several attempts to increase PLA crystallinity have been reported, with the intention of optimising properties such as strength, stiffness and heat resistance. However processability and impact strength cannot readily be improved and in some cases were adversely affected $[6,7]$.

Toughening PLA by blending it with other materials has also been attempted by several researchers [8]. Toughness is defined as the amount of energy that a material can absorb before it breaks and the relatively low impact strength of PLA is considered a limitation in many applications. Polycaprolactone has been widely blended with PLA, because of its nontoxicity and biocompatibility [9]. Depending on the molecular weight of both materials, immiscible blends can be formed, given the lack of the specific interactions between them [10]. Most attempts at blending PLA with PCL resulted in an increase in toughness but a decrease in strength and stiffness [11-13]. Todo et al added 5, 10 and $15 w t \%$ loadings of PCL to PLA to investigate the micro-fracture mechanisms of the blends. The materials were found to be immiscible, with PCL being dispersed in spherical phases within the PLA [14]. Ostafinska et al examined the properties of PLA-PCL blends, where PLA grades with different viscosity values were blended with $20 \%$ PCL [15]. Results showed that the viscosity of PLA influenced the PCL particle size and distribution. This had an effect on toughness and viscosity of the blends.

Polybutylene succinate is a long chain polyester with $\mathrm{Tg}$ of $-32 \mathrm{C}^{\circ}, \mathrm{Tm}$ of $114-115 \mathrm{C}^{\circ}$, high HDT and elongation at break. In general, PLA and PBS have similar properties, with PBS being more flexible, with lower strength and higher toughness [16]. Linear PBS has higher mechanical properties and elongation at break, whereas long chain branched PBS has a lower melt flow rate and tensile properties [17]. In general PBS has been found to increase the toughness of PLA at low concentrations and slightly increase the heat deflection temperature [16]. At similar molecular weights, PBS and PLA are thermodynamically miscible, but when blended in higher concentrations immiscibility occurs. The morphology and thermal properties of PLA-PBS blends have been studied in detail [18-20], where semi-crystalline/semi-crystalline blends were observed with two distinct melting peaks. Small angle $X$-ray scattering revealed that within the blend the PBS component was expelled from interlamellar regions of PLA. It was also found that PBS affected the cold crystallisation of PLA and its melting behaviour. This was explained by the thermodynamic immiscibility of the two materials [21]. However, it showed that PBS had a nucleating effect in PLA and that the viscosity of PLA was increased at low frequencies. This could be explained by the research of Yokohara and Yamaguchi [19] where it is stated that the entanglement molecular weight of PLA was lower than that of PBS due 
to their immiscibility in the molten state. Additional studies showed that the droplets of PBS inside PLA acted as crystallisation nuclei for PLA, accelerating crystal formation [20]. At an addition of $1 \%$ of PBS in PLA, the produced blend had higher strength and modulus [22]. The relative viscosities of the two materials affected the co-continuous morphology of the blend with PBS having a more fibriliar phase structure inside PLA. This resulted in increase of ductility. However the strength and modulus decreased as the amount of PBS increased [23].

It is clear from the literature that both PCL and PBS have been used extensively to increase the toughness of PLA and influence its melt behaviour. Generally, higher fractions of PBS or PCL resulted in better impact resistance but at the cost of reduced mechanical strength and stiffness. The effect of tertiary blends of PLA, PCL and PBS however, is less well understood. In this study, a commercial grade of PLA was blended with PCL and PBS in both binary and ternary formulations, with the aim of increasing toughness without significant reduction in mechanical properties.

\section{Methods}

\subsection{Sample preparation}

PLA matrix material (Ingeo ${ }^{\mathrm{TM}}$ 4043D, 98\% L content) was acquired from NatureWorks LLC, USA . PCL (CAPA 6250) with molecular weight of $25,000 \mathrm{~g} / \mathrm{mol}$ was acquired from Innovia Solutions (UK) and PBS (Mitsubishi FZ91PD) were acquired from Mitsubishi chemical Corp (MW of 123,000 g/mol). All polymers were received in pellet form. $3.5 \mathrm{~kg}$ of each blend was extruded using an APV $19 \mathrm{~mm}$ twin screw extruder with L: $D$ ratio of 25:1. The materials were mixed prior to processing and dried under vacuum at $45^{\circ} \mathrm{C}$ for $24 \mathrm{hrs}$. The materials were then fed into the hopper at a rate of $1.44 \mathrm{~kg} / \mathrm{hr}$ and extruded at a screw rotation speed of $170 \mathrm{rpm}$ before being quenched in a water bath at room temperature and pelletized. The temperature profile of the heating zones with a direction from hopper to die was $160^{\circ} \mathrm{C} \rightarrow 170^{\circ} \mathrm{C} \rightarrow 180^{\circ} \rightarrow 180^{\circ} \rightarrow 190^{\circ} \mathrm{C}$. Pure PLA and 16 PLA blends were produced; Table 1 displays the formulation of each blend. Each blend was then dried under the same conditions and tensile specimen bars dimensions (parallel length/thickness/width: 80/4/10 mm) were produced using a Fanuc s-200i $100 \mathrm{~A}$ injection moulding machine at a mould temperature of $30^{\circ} \mathrm{C}$ for the IZOD impact and morphology tests. Moulding conditions are shown in Table 2. For the tensile tests a Dr Collin Teach-Line E 20T sheet extruder was used with a screw speed of $70 \mathrm{rpm}$ and a temperature profile of the heating zones with a direction from hopper to die was $140^{\circ} \mathrm{C} \rightarrow 150^{\circ} \mathrm{C} \rightarrow 190^{\circ} \rightarrow 200^{\circ} \rightarrow 200^{\circ} \mathrm{C}$. The formulation of each blend will be denoted with the following coding: (PLA wt\%, PBS wt\%, PCL wt\%).

\begin{tabular}{|l|c|c|c|c|c|c|c|c|c|c|c|c|c|c|c|c|c|}
\hline $\begin{array}{l}\text { PLA } \\
\text { wt } \%\end{array}$ & 100 & 95 & 90 & 80 & 70 & 95 & 90 & 80 & 70 & 98 & 90 & 85 & 85 & 85 & 85 & 80 & 70 \\
\hline $\begin{array}{l}\text { PBS } \\
\text { wt } \%\end{array}$ & 0 & 5 & 10 & 20 & 30 & 0 & 0 & 0 & 0 & 1 & 5 & 10 & 14 & 5 & 1 & 10 & 15 \\
\hline $\begin{array}{l}\text { PCL } \\
\text { wt } \%\end{array}$ & 0 & 0 & 0 & 0 & 0 & 5 & 10 & 20 & 30 & 1 & 5 & 5 & 1 & 10 & 14 & 10 & 15 \\
\hline
\end{tabular}

Table 1 Formulation of binary and ternary PLA based bio-compounds

\begin{tabular}{|l|l|l|} 
Injection settings & Extrusion settings & $\begin{array}{c}\text { Temperature } \\
\text { settings }\end{array}$ \\
\hline
\end{tabular}




\begin{tabular}{|l|l|l|l|l|l|}
\hline $\begin{array}{l}\text { Injection } \\
\text { speed }\end{array}$ & $\begin{array}{l}50 \\
(\mathrm{~mm} / \mathrm{s})\end{array}$ & $\begin{array}{l}\text { Back } \\
\text { pressure }\end{array}$ & $\begin{array}{l}40 \\
(\text { Bar })\end{array}$ & $\begin{array}{l}\text { Feed } \\
\text { zone }\end{array}$ & $\begin{array}{l}35 \\
{ }^{\circ} \mathrm{C}\end{array}$ \\
\hline $\begin{array}{l}\text { Position } \\
\text { transfer }\end{array}$ & $\begin{array}{l}10 \\
(\mathrm{~mm})\end{array}$ & Speed & $\begin{array}{l}100 \\
\mathrm{rpm}\end{array}$ & Zone 1 & $\begin{array}{l}140 \\
{ }^{\circ} \mathrm{C}\end{array}$ \\
\hline $\begin{array}{l}\text { Pack } \\
\text { pressure }\end{array}$ & $\begin{array}{l}500 \\
(\text { Bar })\end{array}$ & $\begin{array}{l}\text { DCMP } \\
\text { distance }\end{array}$ & $5(\mathrm{~mm})$ & Zone 2 & $\begin{array}{l}180 \\
{ }^{\circ} \mathrm{C}\end{array}$ \\
\hline $\begin{array}{l}\text { Packing } \\
\text { time }\end{array}$ & $30(\mathrm{sec})$ & $\begin{array}{l}\text { DCMP } \\
\text { velocity }\end{array}$ & $\begin{array}{l}5 \\
(\mathrm{~mm} / \mathrm{s})\end{array}$ & Zone3 & $\begin{array}{l}200 \\
{ }^{\circ} \mathrm{C}\end{array}$ \\
\hline Shot size & $\begin{array}{l}33 \\
(\mathrm{~mm})\end{array}$ & Cool time & $\begin{array}{l}12 \\
(\mathrm{sec})\end{array}$ & nozzle & $\begin{array}{l}200 \\
{ }^{\circ} \mathrm{C}\end{array}$ \\
\hline
\end{tabular}

Table 2 injection moulding conditions

\subsection{Characterisation techniques}

The viscosity of the blends was measured using a Rosand RH10 twin bore capillary rheometer at a set temperature of $200^{\circ} \mathrm{C}$. Tests comprised 8 stages with shear rates ranging from 50 to $5,000 \mathrm{~s}^{-1}$ using $1 \mathrm{~mm}$ diameter dies with lengths of $16 \mathrm{~mm}$ and $<0.2 \mathrm{~mm}$. Three tests were attempted for each blend which were dried prior to testing in a vacuum oven at $45^{\circ} \mathrm{C}$ for $24 \mathrm{hrs}$. Tensile properties of the materials were evaluated using a Messphysik 20-10 tensometer equipped with a video extensometer (pixelink 2.3 Mono $92 \mathrm{Fps}$ ) for more accurate measurement of strain. Five specimens of each blend with dimentions of (width $x$ thickness $x$ gauge length) $2(\mathrm{~mm}) \times 0.5(\mathrm{~mm}) \times 10(\mathrm{~mm})$ were characterised by calculating the modulus of elasticity, tensile strength and strain at break. A strain rate of $1 \%$ was set $(8 \mathrm{~mm} / \mathrm{min}$ test speed) and 7 targets (black lines) were drawn in the parallel length of each specimen for the video extensometer to detect.

Impact strength of the blends was measured using an Instron Dynatup POE 2000. Five IZOD (pendulum) impact tests performed for each blend. The injection moulded specimens were notched in the middle of the gauge section $(2 \mathrm{~mm} \pm 0.2)$ and the impact strength was calculated based on equation (1) where the area under the curve of the load-deflection diagram ( $E_{T}=$ total impact energy) was divided by the nominal impact area of the specimen (area of the notch in $\mathrm{mm}^{2}$ ).

$$
a_{i N}=\frac{\mathrm{E}_{T}}{h \times b} \times 10^{3}
$$

Differential scanning calorimetry (DSC) tests were performed using a Discovery TA Q20 instrument, with a heat-cool-heat step process of $10^{\circ} \mathrm{C} / \mathrm{min}$ heating rate from $20-220^{\circ} \mathrm{C}$ under $50 \mathrm{ml} / \mathrm{min} \mathrm{N}_{2}$ supply. Measurements were made on three $\sim 10 \mathrm{mg}$ specimens cut from the gauge length of the tensile bars of each blend. Morphology of the materials was investigated using an FEI Quanta 400 scanning electron microscope. Moulded bars were cryo-fractured under liquid nitrogen in the middle of the gauge section and subsequently gold plated ( 2 minutes spattering of $25 \mathrm{~mA}$ current) prior to SEM analysis of the fracture surface.

\section{Results and discussion}

\subsection{Rheological properties}

To provide a quantitative comparison of rheological data, apparent shear viscosity measured at a constant shear rate of $360 \mathrm{~s}^{-1}$ is shown in Figure 1 for all blends. Viscosity of binary blends containing $\mathrm{PCL}$ followed a linear reduction with increase in wt\% of PCL, in agreement with the conclusions of $\mathrm{Wu}$ et al. [24] and Zhao et al. [25]. PBS had a less significant effect on viscosity reduction, and at $5 \mathrm{wt} \%$ an increase in viscosity was observed, which may be an indication of the immiscibility of the two materials in the molten state $[19,26]$. The effects of PCL and PBS on viscosity could be explained by the different density and melting points of the polymers $\left(\operatorname{Tm}_{(\mathrm{PCL})}=55^{\circ} \mathrm{C}\right.$ and $\left.\operatorname{Tm}_{(\mathrm{PBS})}=110^{\circ} \mathrm{C}\right)$. For ternary blends, incorporation of PCL and PBS had an additive effect on observed viscosity, broadly in 
line with what would be expected from the binary blend results. For example, the $(80,10,10)$ blend exhibited a viscosity between the values measured for $(80,20,0)$ and $(80,0,20)$.

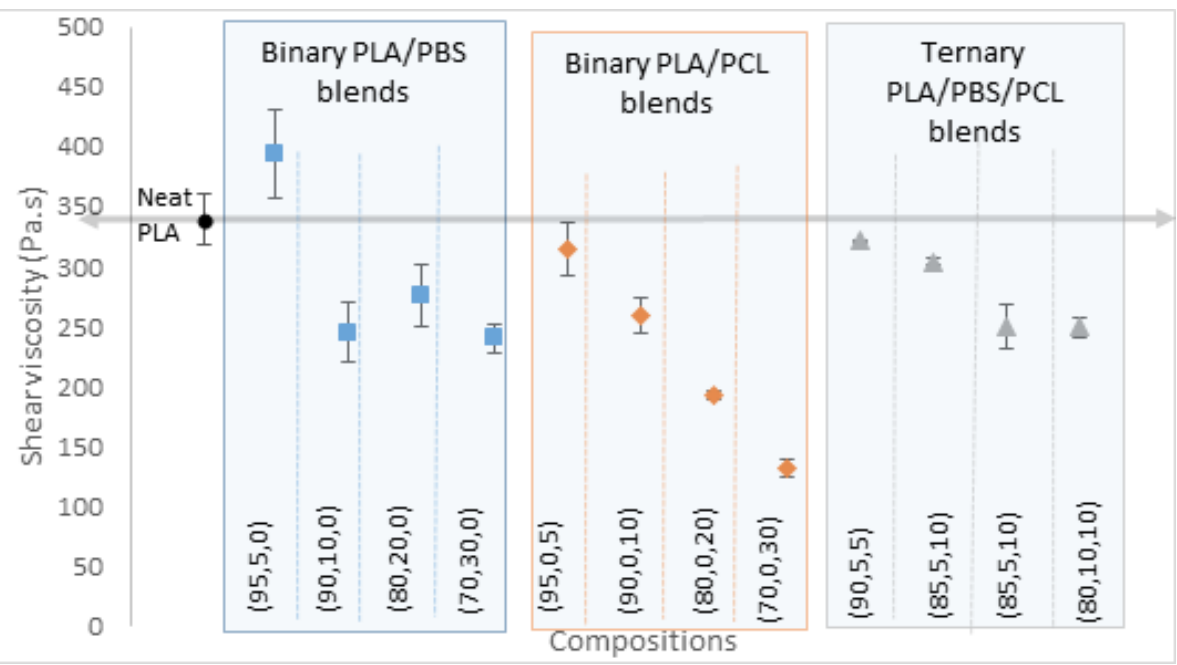

Figure 1 Shear viscosity of PLA based blends at $360\left(\mathrm{~s}^{-1}\right)$ shear rate from capillary rheometry at $200^{\circ} \mathrm{C}$ (error bars indicating the Standard deviation between the three test runs of each blend.

\subsection{Mechanical properties}

Impact strength results are displayed in Figure 2, which showed that incorporation of PCL and PBS resulted in a significant increase in impact strength compared to pure PLA. As expected, neat PLA exhibited a relatively low impact strength of $2.18\left(\mathrm{~kJ} / \mathrm{m}^{2}\right)$, but blends of $\mathrm{PCL}$ and PBS even at low loadings resulted in higher toughness. PCL had a more significant effect on impact strength and at $30 w t \%$ loading the blend had an impact strength of double that of neat PLA. PBS had a less significant effect on impact strength, with 30wt\% loading of PBS providing an increase of around $50 \%$. Ternary blends exhibited impact strengths in between those containing PCL and PBS alone. However, at low loadings of both polymers, for example $(90,5,5)$ the impact strength was higher by $38 \%$ and $8 \%$ than corresponding binary blends containing $10 \mathrm{wt} \%$ of PBS and PCL respectively, which suggests that addition of PBS had a synergistic effect to PCL alone.

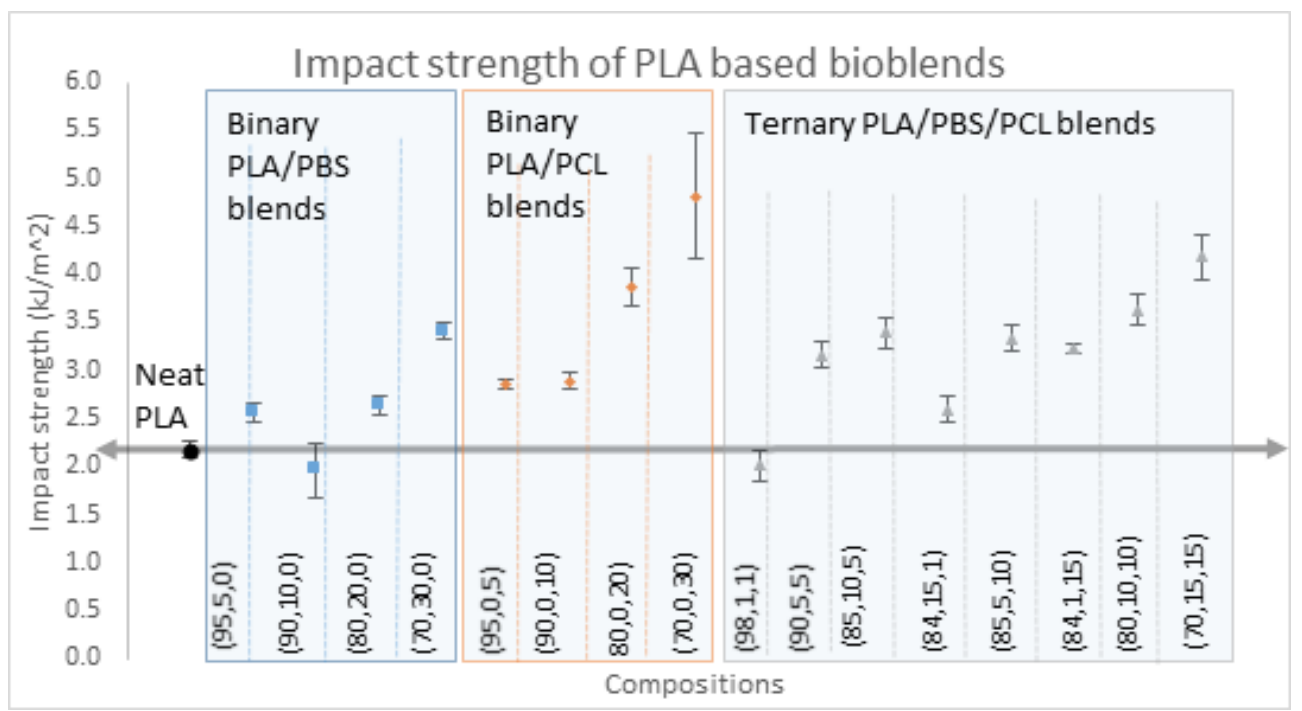

Figure 2 Impact strength results ( 5 repeats for each blend with standard deviation described by error bars) of PLA based bio-compounds, by IZOD impact test with $90^{\circ}$ drop angle and average impact velocity of $3.5(\mathrm{~m} / \mathrm{s})$. 
Elastic modulus and tensile strength results are shown in Figure 3; broadly similar trends were observed for each set of data. Addition of both PCL and PBS resulted in a decrease in elastic modulus and tensile strength of PLA as loading increased, with PCL having a more significant effect. At low loadings, binary blends exhibited an elastic modulus around $18-20 \%$ lower than neat PLA, which decreased to $40 \%$ lower at $30 \mathrm{wt} \%$ loading of $\mathrm{PCL}$ in agreement with previous findings $[13,25]$. The binary blends containing PBS exhibited a slight decrease in tensile strength at a relatively constant rate from $7 \%$ to $13 \%$ decrease. Whereas the binary blends containing PCL had a more significant decrease in strength. Ternary blends containing both PCL and PBS also exhibited a reduction in modulus and tensile strength, broadly in between those of the two binary blends. However, at low loadings of both polymers, for example $(90,5,5)$, both elastic modulus and tensile strength values were higher by nearly $10 \%$ than corresponding binary blends containing $10 \%$ of the two polymers. This again suggested a beneficial interaction between the PBS and PCL within the PLA matrix which correlated to the observations made on impact strength.

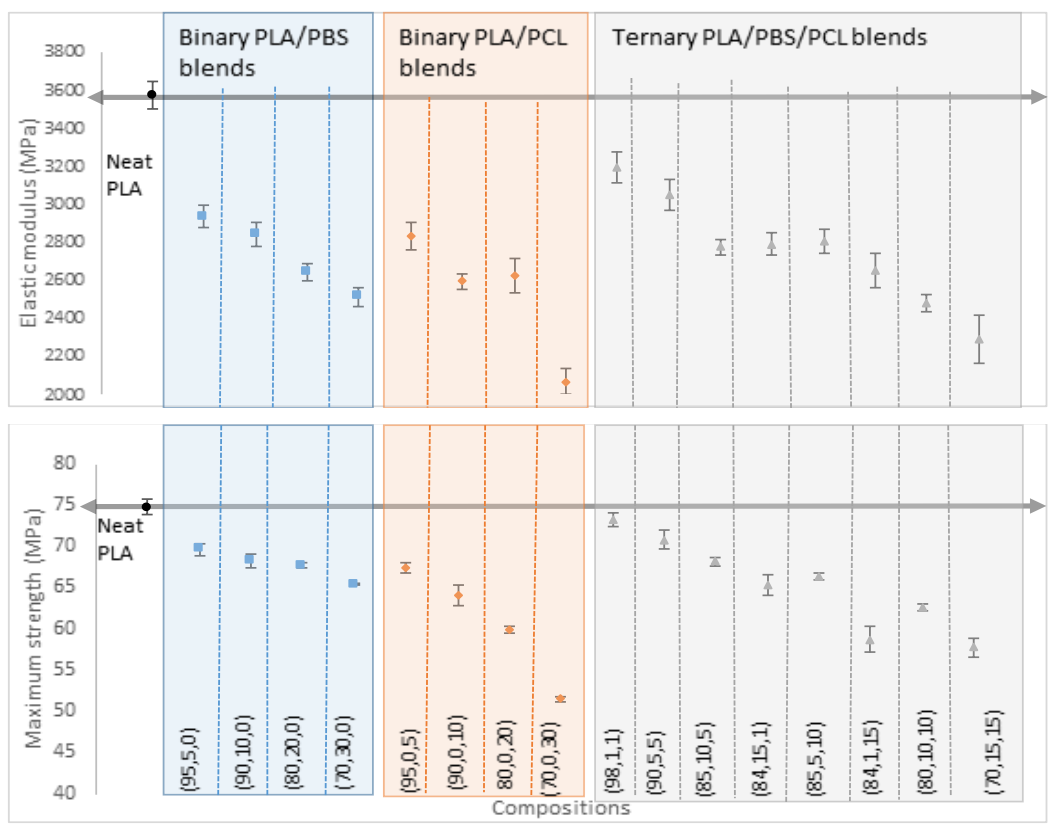

Figure 3 Elastic modulus (above) and tensile strength (below) results of all PLA-based blends from tensile testing with 1\% strain rate and use of video extensometer (the standard deviation of the tensile properties for each blend is indicated by the bars)

As shown in Figure 4, strain at break increased as the amount of PBS increased in PLA with values from $25 \%$ to $454 \%$. On the contrary the binary blends containing PCL had higher values (206\%) of strain at break at the lowest loading $(95,0,5)$ and as the amount of PCL increased, toughness decreased, where eventually at $20 \%$ and $30 \%$ loadings toughness was lower than that of neat PLA. The blends that consisted of both of the additives presented an impressively increase in strain at break, even at low loadings. Where formulations that had wt\% of PBS from 5-15\% of PBS exhibited strain at break of $350 \%-450 \%$. However, when the amount of PCL was $10 \%$ or higher blends, exhibited lower values, which follows the effect of $\mathrm{PCL}$ in the binary blends results. This indicates a limitation on the toughening mechanism of PCL in PLA regarding elongation at loadings of $10 \%$ and higher. 


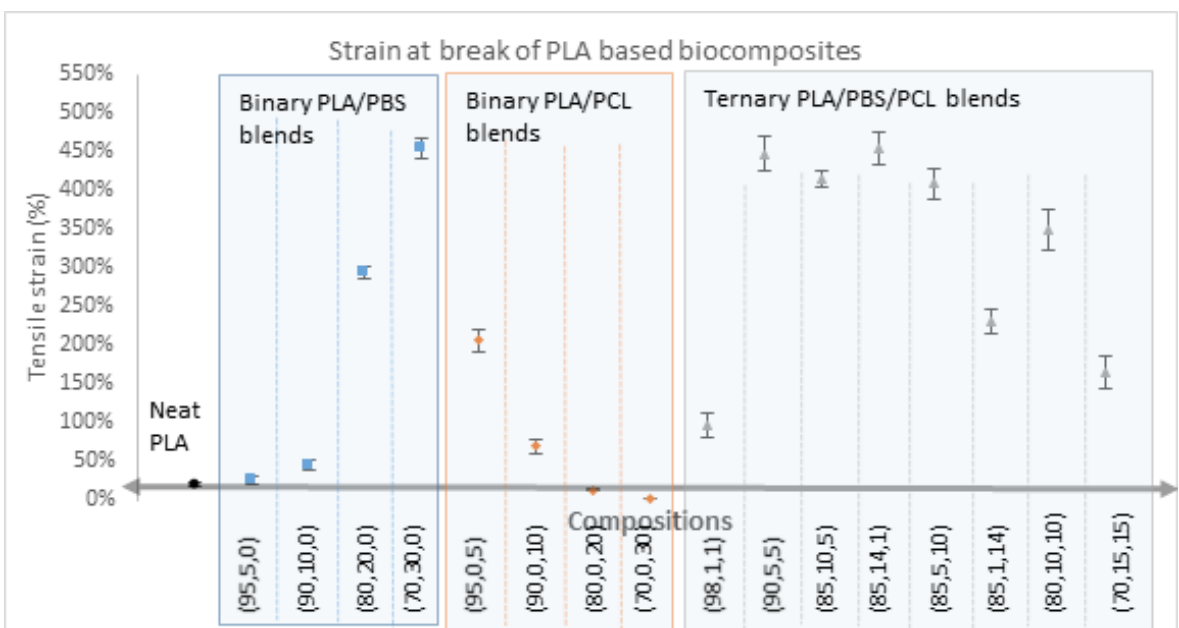

Figure 4 Strain at break results of all PLA-based blends from tensile testing with $1 \%$ strain rate and use of video extensometer (the value range of the tensile properties for each blend is indicated by the bars)

\subsection{Thermal properties}

DSC results from a heat-cool-heat $(\mathrm{HCH})$ cycle of $10^{\circ} \mathrm{C} / \mathrm{min}$ from $20-220^{\circ} \mathrm{C}$ are displayed for neat PLA in Figure 5. On first heating, a deep transition was observed at around $60^{\circ} \mathrm{C}$, indicating a relaxation peak (aging) of enthalpy (Eg) which was also observed during second heating cycles at a lower magnitude [17]. Upon further heating PLA exhibited a crystallisation exotherm between 100 $130^{\circ} \mathrm{C}$ before melting at $151^{\circ} \mathrm{C}$. On cooling, crystallisation was not observed but a characteristic glass transition occurred at $57^{\circ} \mathrm{C}$. Similar behaviour was observed during second heating but with a less pronounced relaxation endotherm at around $60^{\circ} \mathrm{C}$.

\begin{tabular}{|c|c|c|c|c|c|c|c|c|}
\hline Material/blend & 1st he: & & & Coolir & & 2nd h & & \\
\hline PLA,PBS,PCL & $\begin{array}{l}\mathbf{T g} \\
{ }^{\circ} \mathbf{C} \\
\end{array}$ & $\begin{array}{l}\text { Tcc } \\
{ }^{\circ} \mathrm{C} \\
\end{array}$ & $\begin{array}{l}\mathbf{T m} \\
{ }^{\circ} \mathbf{C} \\
\end{array}$ & $\begin{array}{l}\mathrm{Tg} \\
{ }^{\circ} \mathrm{C} \\
\end{array}$ & $\begin{array}{l}\text { Tc } \\
{ }^{\circ} \mathrm{C} \\
\end{array}$ & $\begin{array}{l}\mathrm{Tg} \\
{ }^{\circ} \mathrm{C} \\
\end{array}$ & $\begin{array}{l}\text { Tcc } \\
{ }^{\circ} \mathbf{C} \\
\end{array}$ & $\begin{array}{l}\mathbf{T m} \\
{ }^{\circ} \mathbf{C} \\
\end{array}$ \\
\hline Virgin PLA & 62 & N/A & 151 & 57 & N/A & 60 & N/A & 152 \\
\hline Virgin PBS & N/A & N/A & 115 & N/A & 66 & N/A & N/A & 114 \\
\hline Virgin PCL & N/A & N/A & 66 & N/A & 28 & N/A & N/A & 56 \\
\hline$(100,0,0)$ & 62 & 112 & 149 & 57 & N/A & 59 & 113 & 149 \\
\hline$(95,5,0)$ & 61 & 105 & 150 & 56 & N/A & 59 & 110 & 148 \\
\hline$(90,10,0)$ & 60 & 103 & 153 & 56 & N/A & 59 & 109 & 148 \\
\hline$(80,20,0)$ & 60 & 104 & 149 & 56 & 61 & 59 & 117 & 149 \\
\hline$(70,30,0)$ & 60 & 101 & 149 & N/A & 70 & 58 & 119 & 148 \\
\hline$(95,0,5)$ & 61 & 109 & 148 & 57 & 28 & 60 & 129 & 152 \\
\hline$(90,0,10)$ & 60 & 107 & 149 & 58 & 35 & 61 & 126 & 151 \\
\hline$(80,0,20)$ & 60 & 104 & 149 & 56 & 35 & 59 & 117 & 149 \\
\hline$(70,0,30)$ & 61 & 108 & 147 & 58 & 34 & 61 & 126 & 150 \\
\hline$(90,5,5)$ & 60 & 104 & 149 & 47 & 31 & 60 & 127 & 151 \\
\hline$(85,10,5)$ & 60 & 103 & 149 & 57 & 32 & 60 & 126 & 151 \\
\hline$(85,5,10)$ & 61 & 103 & 151 & 57 & 29 & 62 & 123 & 150 \\
\hline$(80,10,10)$ & 59 & 104 & 148 & 57 & 36 & 62 & 125 & 151 \\
\hline
\end{tabular}

Table 3 Overall temperature transition results, from DSC tests (Heat-Cool-Heat). Cycles with Ramp $10^{\circ} \mathrm{C} / \mathrm{min}$ from $20-220^{\circ} \mathrm{C}$. 
Table 3 shows the average temperature values extracted from DSC data for all blends. Virgin materials were characterised in as-received pellet form as well as injection moulded samples of PLA and all blends. There was a notable difference in thermal behaviour between the virgin PLA and an injection moulded specimen produced from the same material; the virgin PLA did not exhibit any crystallisation peak during the three cycles. This could be explained from the morphology of the pellets which were highly crystalline, compared to the moulded bar which was predominantly amorphous. Virgin PBS and PCL during the same heating cycles exhibited only melting peaks when heated (at 115 and $66^{\circ} \mathrm{C}$ respectively). During cooling a crystal formation peak occurred at $66^{\circ} \mathrm{C}$ for PBS and $28^{\circ} \mathrm{C}$ for PCL. This means that PCL was melting during the Glass transition of PLA and PBS during the cold crystallisation of PLA and both additives exhibited crystal formation during cooling around the glass transition temperature of PLA.

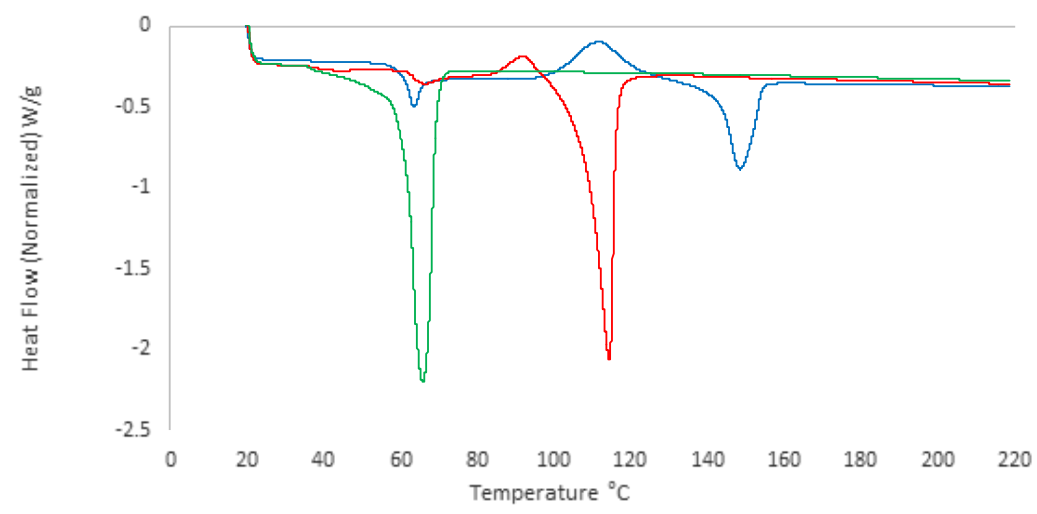

(a)

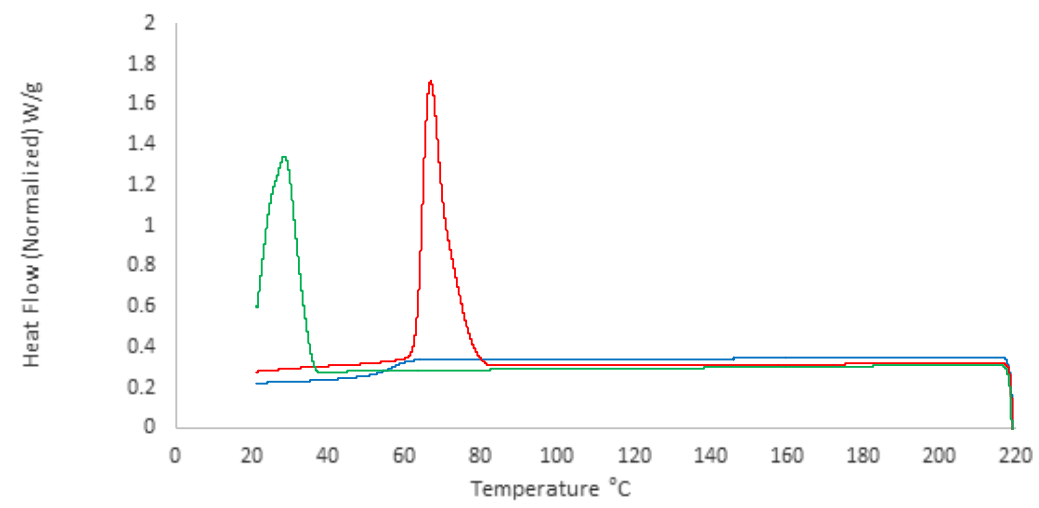

(b)

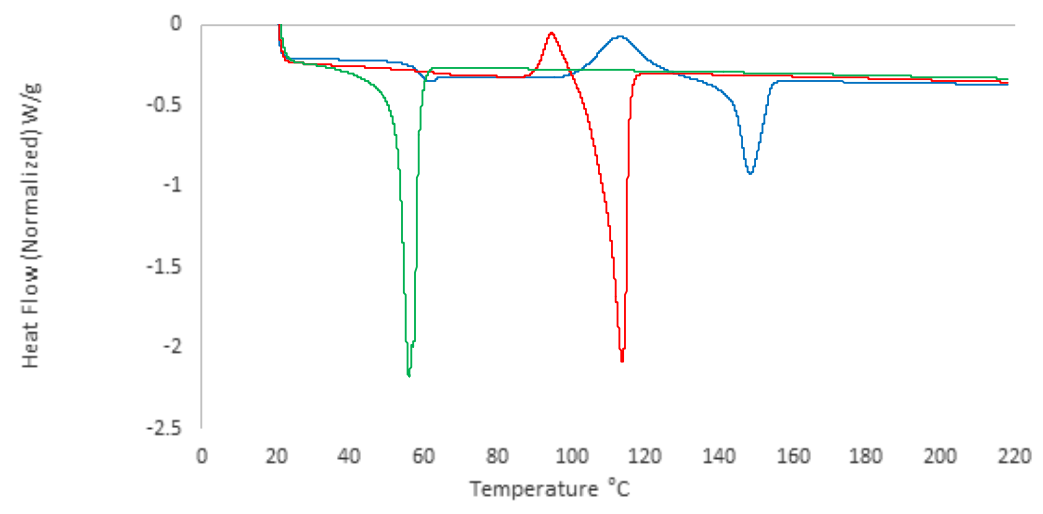

(C) 
Representative DSC thermograms are shown in Figure 6 for neat PLA, 10wt\% loading of each binary blend and the $(80,5,5)$ ternary blend. Second heating values were used to compare each material with an identical thermal history. A slight decrease in the glass transition temperature was observed in the binary PLA-PBS blends, whereas Tg values from the blends containing PCL exhibited a slight increase. This could be explained by the fact that PCL melted close to the glass transition temperature of PLA, as shown in Figure 5. The binary blend containing PBS (Figure 6b) appeared to have an overlapped peak around the cold crystallisation temperature, indicating that in the blend at the temperature region of $90-130^{\circ} \mathrm{C}$ PLA crystals were formed and PBS was melting.

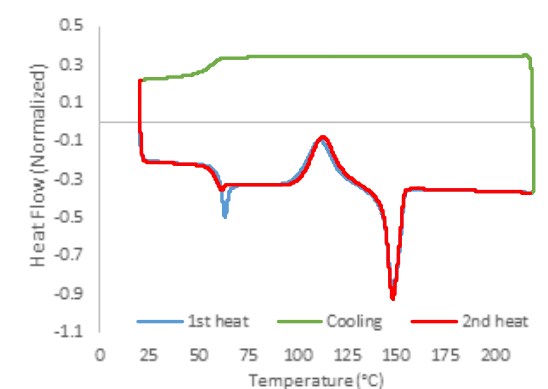

(a)

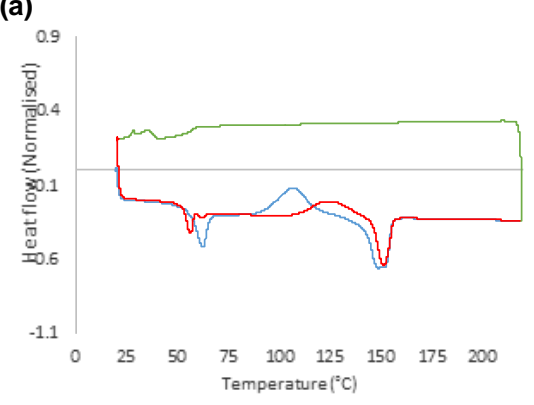

(c)

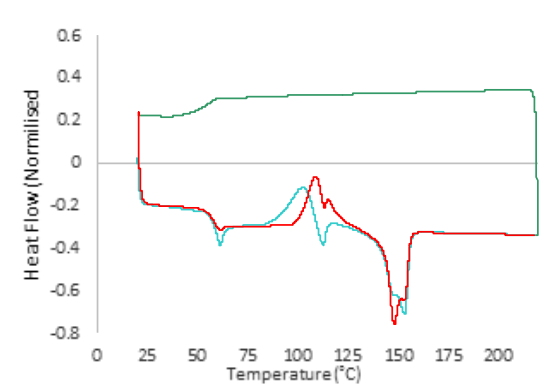

(b)

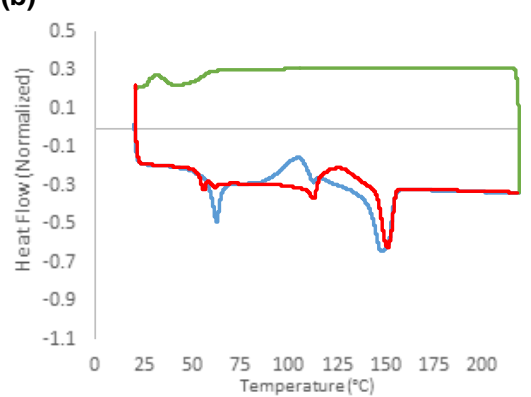

(d)

Figure 6 DSC graphs of neat PLA (a), binary blends "b" $(90,10,0)$ and "c" $(90,0,10)$ and ternary blend "d" with formulation $(90,5,5)$.

The binary PCL blends exhibited thermal immiscibility, with the melting peak of PCL occurring at a similar temperature region as the glass transition of PLA $\left(55^{\circ} \mathrm{C}\right)$ [27]. The crystallisation peak of PLA was affected by the addition of $\mathrm{PCL}$, during the first heat cycle the crystallisation peak temperature decreased by $4^{\circ} \mathrm{C}$ and by $20^{\circ}$ during the second heat. $\mathrm{PCL}$ exhibited a recrystallisation peak in all the binary blends during cooling (at $28^{\circ} \mathrm{C}$ ), which increased as the wt\% of the additive also increased. The thermal compatibility of the additives on the ternary blends did not change, exhibiting distinct but overlapping peaks with the glass transition and crystallisation of PLA.

\subsection{Morphology}

SEM images of the fracture surfaces of PLA/PBS and PLA/PCL binary blends are shown in Figure 7 PLA/PBS blends at loadings of $5 w t \%$ and $30 w t \%$ are shown in Figures $7 a$ and $7 c$ respectively. These indicate that PBS was immiscible within PLA, particularly at higher loadings. Figures $7 \mathrm{~b}$ and $6 \mathrm{~d}$ show that PCL was also immiscible with PLA, evidenced by voids on the fracture surface, suggesting that $P C L$ was dispersed in spherical droplets with diameters less than $0.5 \mu \mathrm{m}$ [14]. At higher amounts of PCL (30 wt\%, Figure 6d), PCL spheres increased in size (diameter $\sim 1-2 \mu \mathrm{m}$ ) and the fracture surface demonstrated a more rugged, stepped pattern more similar to PBS[28]. As previously shown, the addition of PCL had a more significant effect on the properties of PLA than PBS, including viscosity and impact strength. During impact, The PCL spheres dispersed inside the blend system absorb energy applied to the specimen. This morphology, according to [14], increases the craze formation, so the $\mathrm{PCL}$ spheres act as a damper inside the material. When under tension though this discontinuous 
morphology reduces the strength and stiffness of the material. Resulting in the decreasing effect of strain at break as the amount of PCL increased. Although PBS was also found to be immiscible with PLA, the SEM results showed that PBS segments were dispersed inside PLA [29]. At the 5\% PBS added binary blend, a slight increase in viscosity was observed. This was because the immiscibility between the two materials at that additive loading was not that notable, and it has been stated that at low loadings of PBS, due to the molecular entanglement of the two materials viscosity can increase [22, 26]. The shape of the dispersed PBS inside the PLA blend system, explains why the additive modifies the mechanical properties of PLA but not at the same rate as with PCL.
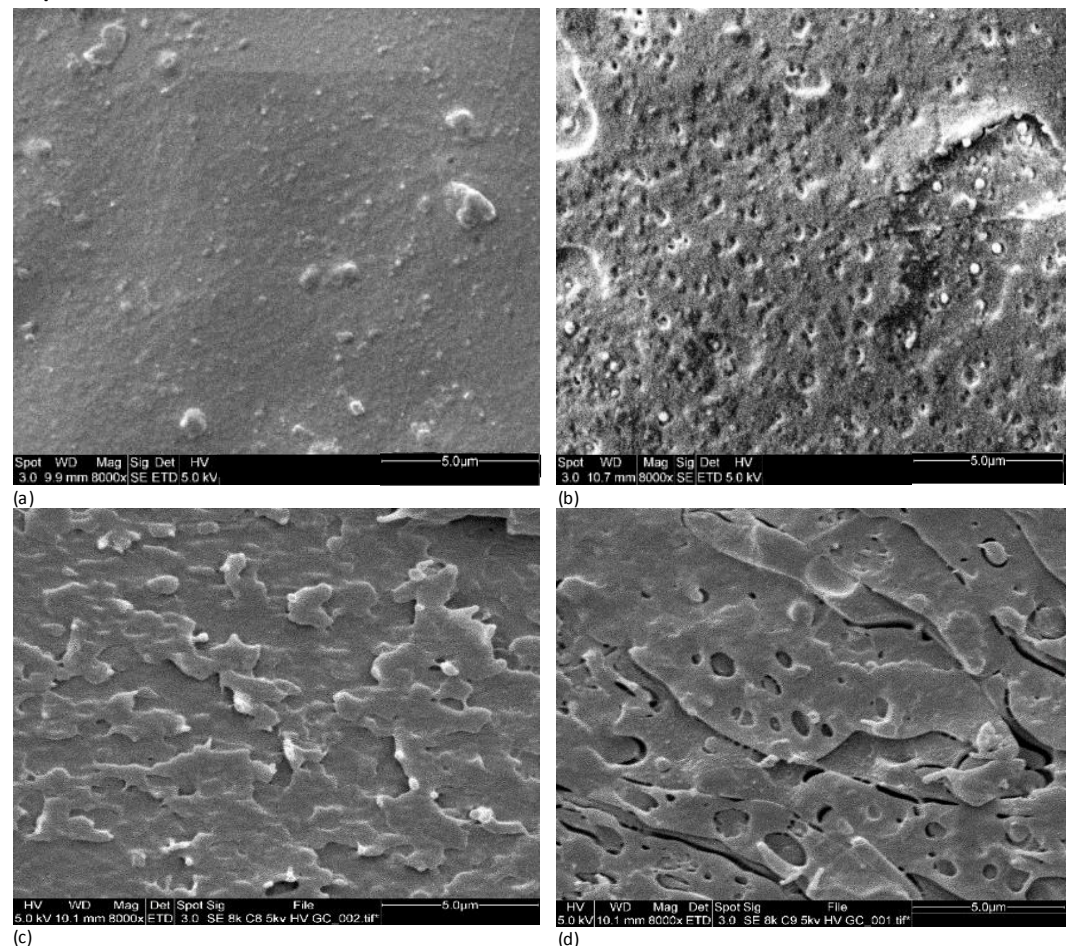

Figure 7 SEM images from the cross section of the bars at $8000 x$ magnification. Binary blend $(95,5,0)$ is image (a), binary blend with $5 \%$ $\operatorname{PCL}(95,0,5)$ is image $(b),(70,30,0)$ and $(70,0,30)$ are images (c) and (d) respectively.

This type of miscibility can explain why PBS was so effective in increasing strain at break of PLA, the blend matrix had a bonding material dispersed inside, which during tension promoted the formation of necking, therefore increase in toughness. Whereas PCL compromised the structure of the matrix material, so during tension the voids increased in size in a fibriliar way that resulted in tearing the samples.
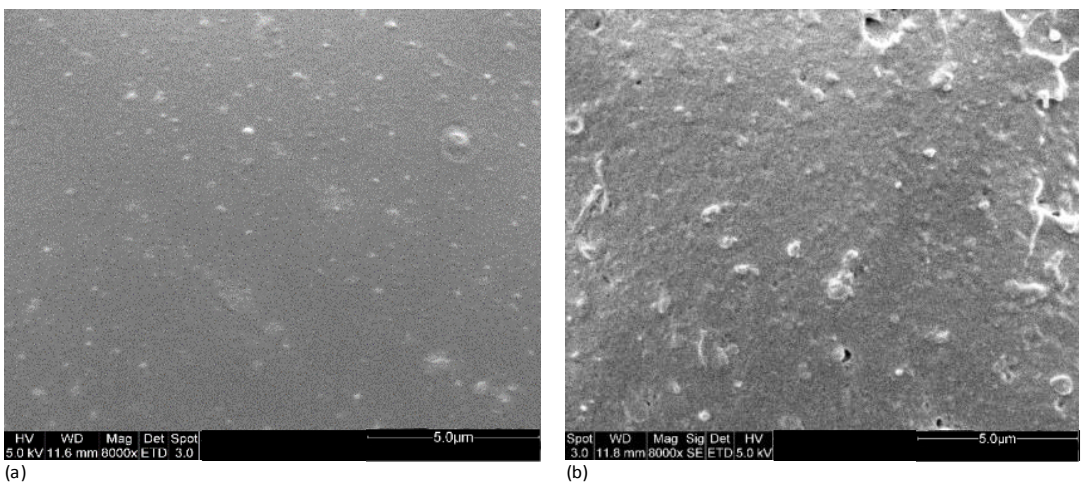

Figure 8 SEM images from the cross section of the bars at $8000 x$ magnification ( $a=n e a t$ PLA, $b=$ ternary blend $(90,5,5)$ ). 
When both additives were blended with PLA at $5 \%$ loading, as shown in Figure 8 , immiscibility was less pronounced than compared to $5 \mathrm{wt} \%$ of either PCL or PBS. The fractured surface exhibited smaller sized and less voids. This suggested that droplets of PCL had some interaction with the PBS within the blend system. This explains why the impact strength of the ternary blend that contained $90 \%$ of PLA $(90,5,5)$ was higher than the impact strength of the binary ones $(90,10,0)$ and $(90,0,10)$. This phenomenon could be parallelised with Nagarajan's theory, who stated that the balance between the entanglement density and the number of the skeletal bonds in an entanglement strand effects the nature of fracture of the blend (either yielding or crazing)[30]. By adding both materials these two factors were changed, which provided different results than when blended singularly. This structure resulted in maintaining the strength of PLA during tension, especially for the $(90,5,5)$ formulation.

\section{Conclusion}

A range of binary and ternary commercial grade PLA based blends were compounded using a twin screw extruder, and injection moulded tensile bars were produced for characterisation of impact properties and phase separation. This investigation showed that the suggested formulation would be an incorporation of a small amount of both of the additives (PLA=90 wt\%,PBS=5 wt\%,PCL=5wt\%), a blend that had increased toughness without a significant reduction in strength and stiffness. Both additives acted as melt modifiers, with PCL having a more linear plasticising effect in PLA than PBS. The impact strength of PLA was increased with addition of either PBS or PCL, more significantly for $P C L$, but strength and stiffness were reduced. The additives were not thermally compatible in either binary or ternary blends. PCL was observed to be dispersed in a spherical form inside PLA with a particle size which increased as the additive loading increased. PBS was dispersed as larger, less regular shaped particles inside the blend matrix. When both additives were blended with PLA, the PCL sphere size was reduced significantly. This change in morphology had a synergistic effect on both impact strength and tensile properties of the blend, especially at the $(90,5,5)$ formulation, indicating a compatibilising effect of PBS in the PLA/PCL blend.

\section{Acknowledgements}

The autors wish to thank the financial support of Floreon- Transforming Packaging Ltd through the PhD sponsorship and materials provision and the University of Bradford Polymer IRC technical staff for their help and guidence.

\section{References}

[1] Ahmed T, Shahid M, Azeem F, Rasul I, Shah A, Noman M, Hameed A, Manzoor N, Manzoor D I and Muhammad S 2018 Biodegradation of plastics: current scenario and future prospects for environmental safety vol 25

[2] Madigan M T, Martinko J M and Parker J 2000 Brock biology of microorganisms (Upper Saddle River, NJ: Prentice Hall)

[3] Van Wouwe P, Dusselier M, Vanleeuw E and Sels B 2016 Lactide Synthesis and Chirality Control for Polylactic acid Production ChemSusChem 9 907-21

[4] Roether J A, Gough J E, Boccaccini A R, Hench L L, Maquet V and Jérôme R 2002 Novel bioresorbable and bioactive composites based on bioactive glass and polylactide foams for bone tissue engineering Journal of Materials Science: Materials in Medicine 13 1207-14

[5] Zhong Y, Zhang Y, Yang J, Li W, Wang Z, Xu D, Chen S and Ding Y 2013 Exponentially increased nucleation ability for poly(L-lactide) by adding acid-oxidized multiwalled carbon nanotubes with reduced aspect ratios Science China Chemistry 56 181-94

[6] Ghosh S, Viana J C, Reis R L and Mano J F 2007 Effect of processing conditions on morphology and mechanical properties of injection-molded poly(I-lactic acid) Polymer Engineering \& Science 47 1141-7

[7] Renouf-Glauser A C, Rose J, Farrar D F and Cameron R E 2005 The effect of crystallinity on the deformation mechanism and bulk mechanical properties of PLLA Biomaterials 26 5771-82 
[8] Krishnan S, Pandey P, Mohanty S and Nayak S K 2016 Toughening of Polylactic Acid: An Overview of Research Progress Polymer-Plastics Technology and Engineering 55 1623-52

[9] Lopes M S, Jardini A L and Filho R M 2012 Poly (Lactic Acid) Production for Tissue Engineering Applications Procedia Engineering 42 1402-13

[10] Navarro-Baena I, Sessini V, Dominici F, Torre L, Kenny J M and Peponi L Design of biodegradable blends based on PLA and PCL: From morphological, thermal and mechanical studies to shape memory behavior Polymer Degradation and Stability

[11] Tsuji H, Yamada T, Suzuki M and Itsuno S 2003 Blends of aliphatic polyestersPart 7. Effects of poly(Llactide-co-\&\#59144;-caprolactone) on morphology, structure, crystallization, and physical properties of blends of poly(L-lactide) and poly(\&\#59144;-caprolactone) Polymer International 52 269-75

[12] Matta A K, Rao R U, Suman K N S and Rambabu V 2014 Preparation and Characterization of Biodegradable PLA/PCL Polymeric Blends Procedia Materials Science 6 1266-70

[13] Vilay V, Mariatti M, Ahmad Z, Pasomsouk K and Todo M 2009 Characterization of the mechanical and thermal properties and morphological behavior of biodegradable poly(L-lactide)/poly( $\varepsilon$-caprolactone) and poly(L-lactide)/poly(butylene succinate-co-L-lactate) polymeric blends Journal of Applied Polymer Science 114 1784-92

[14] Todo M, Park S D, Takayama T and Arakawa K 2007 Fracture micromechanisms of bioabsorbable PLLA/PCL polymer blends Engineering Fracture Mechanics 74 1872-83

[15] Ostafinska A, Fortelný I, Hodan J, Krejčíková S, Nevoralová M, Kredatusová J, Kruliš Z, Kotek J and Šlouf M 2017 Strong synergistic effects in PLA/PCL blends: Impact of PLA matrix viscosity Journal of the Mechanical Behavior of Biomedical Materials 69 229-41

[16] Pivsa-Art W, Fujii K, Nomura K, Aso Y, Ohara H and Yamane H 2016 Isothermal crystallization kinetics of talc-filled poly(lactic acid) and poly(butylene succinate) blends Journal of Polymer Research 23144

[17] Auras R, Lim L-T, Selk S E M and Tsuji H 2010 POLY(LACTIC ACID) SYNTHESIS, STRUCTURES, PROPERTIES, PROCESSING, AND APPLICATION (New Jersey: John Willey \& Sons, Inc)

[18] Anderson K S, Schreck K M and Hillmyer M A 2008 Toughening Polylactide Polymer Reviews 48 85-108

[19] Yokohara T and Yamaguchi M 2008 Structure and properties for biomass-based polyester blends of PLA and PBS European Polymer Journal 44 677-85

[20] Yokohara T, Okamoto K and Yamaguchi M 2010 Effect of the shape of dispersed particles on the thermal and mechanical properties of biomass polymer blends composed of poly(L-lactide) and poly(butylene succinate) Journal of Applied Polymer Science 117 2226-32

[21] Wu D, Yuan L, Laredo E, Zhang M and Zhou W 2012 Interfacial Properties, Viscoelasticity, and Thermal Behaviors of Poly(butylene succinate)/Polylactide Blend Industrial \& Engineering Chemistry Research $512290-8$

[22] Shibata M, Inoue $Y$ and Miyoshi M 2006 Mechanical properties, morphology, and crystallization behavior of blends of poly(I-lactide) with poly(butylene succinate-co-l-lactate) and poly(butylene succinate) Polymer 47 3557-64

[23] Deng Y and Thomas N L 2015 Blending poly(butylene succinate) with poly(lactic acid): Ductility and phase inversion effects European Polymer Journal 71 534-46

[24] Wu D, Zhang Y, Yuan L, Zhang M and Zhou W 2010 Viscoelastic interfacial properties of compatibilized poly(- caprolactone)/polylactide blend Journal of Polymer Science, Part B: Polymer Physics 48 756-65

[25] Zhao H, Yan X, Zhao G and Guo Z 2016 Microcellular injection molded polylactic acid/poly (caprolactone) blends with supercritical CO2: Correlation between rheological properties and their foaming behavior Polymer Engineering and Science 56 939-46

[26] Wang R, Wang S, Zhang Y, Wan C and Ma P 2009 Toughening modification of PLLA/PBS blends via in situ compatibilization Polymer Engineering \& Science 49 26-33

[27] Zhao H and Zhao G 2016 Mechanical and thermal properties of conventional and microcellular injection molded poly (lactic acid)/poly ( $\varepsilon$-caprolactone) blends Journal of the Mechanical Behavior of Biomedical Materials 53 59-67

[28] Yang J-M, Chen H-L, You J-W and Hwang J C 1997 Miscibility and Crystallization of Poly(Llactide)/Poly(ethylene glycol) and Poly(L-lactide)/Poly([epsi]-caprolactone) Blends Polym J 29 657-62

[29] Zolali A M and Favis B D 2017 Partial to complete wetting transitions in immiscible ternary blends with PLA: the influence of interfacial confinement Soft Matter 13 2844-56

[30] Nagarajan V, Mohanty A K and Misra M 2016 Perspective on Polylactic Acid (PLA) based Sustainable Materials for Durable Applications: Focus on Toughness and Heat Resistance ACS Sustainable Chemistry and Engineering 4 2899-916 